\title{
Bioecological characteristics and decorative representatives of the genus Robinia $L$. according to phonological data
}

\author{
Sergey Lazarev*, and Alexandra Semenyutina \\ Federal Research Center of Agroecology RAS, 400062 Volgograd, Prospect University 97, Russia
}

\begin{abstract}
The object of research was the species, varieties and forms of the genus Robinia: R. viscosa var. hartwegii (Koehne) Ashe; R. neomexicana var. rusbyi; R. neomexicana f. pale pink; R. neomexicana $f$. pale purple; R. pseudoacacia L.; R. pseudoacacia f. pyramidalis (Pepin) Rehd.; R. pseudoacacia f. umbraculifera (DC) Rehd. and R. pseudoacacia $x$ R. neomexicana, growing in the dendrological collections of the Federal Research Center of Agroecology, Russian Academy of Sciences. Most of the phenological phases of representatives of the genus Robinia occur at the optimal time for the seasonal development of flowering woody plants. This genus belongs to the group of late beginners and late terminators of the growing season. The indicator of phenological atypicality $(+1-0)$ is in the lower half of the normal area, and for some species and forms (R. viscosa var. Hartwegii, R. pseudoacacia f. Pyramidalis, R. pseudoacacia $f$. Umbraculifera) at the edge of the normal area $(+0.8-+1)$. The research area for these introduced species is the northern border of the wide range of culture and their further promotion to regions with a more severe climate is possible only in experimental plantations or as an additional assortment. The most winter-hardy were the varieties, forms and hybrids of $\mathrm{R}$. neomexicana with a phenological atypicality index from +0.3 to +0.35 . We can recommend these plants for widespread use even in the northern regions of the Volgograd region due to their potential winter hardiness. The study of seasonal rhythms revealed the periods of maximum decorativeness of representatives of the generic complex Robinia, and a comparative characteristic in terms of the beginning and end of flowering. The authors found that R. viscosa var hartwegii has the longest flowering period.
\end{abstract}

\section{Introduction}

Enrichment of the species composition of tree plantations in arid regions is one of the key problems of biological science and practice. Mobilization of the gene pool of cultivated woody plants is especially important when creating modern landscaping facilities in settlements of the Volgograd region.

\footnotetext{
*Corresponding author: hortus@yandex.ru
} 
The gradual deformation of plant areas occurs because of global climate changes [1-3]. These processes are closely related to early onset $[4,5]$ and an increase in the total duration of the growing season $[6,7]$. The scientific substantiation of the expansion of the cultivated areas of plants in the northern direction is possible only considering the bioecological resistance of plants, as well as the economic and decorative value in the conditions of cultivation. Many methods for assessing the adaptation of plants to new conditions of existence are based on the study of the rhythms of seasonal development $[8,9]$. According to phenological observations, we can estimate practically significant indicators of decorativeness: the beginning, duration, and intensity of flowering.

One of the promising generic complexes for the enrichment of the dendroflora of urbanized areas in dry steppe conditions is the genus Robinia. Several species, varieties and forms of this botanical genus are cultivated in the dendrological collections of the Federal Research Center of Agroecology of the Russian Academy of Sciences. Despite the significant representativeness of the tribal complex at the latitude of Volgograd, representatives of this genus are rarely used in landscaping the northern regions of the Volgograd region.

The study aims to assess the bioecological assessment of the possibility of expanding the cultivation areas of species, varieties and forms of the genus Robinia according to phenological observations.

\section{Methods}

We carried out the study based on the dendrological collections of the Federal Research Center of Agroecology of the Russian Academy of Sciences and landscaping objects in Volgograd and Volzhsky in 2015-2020. The object of research was the species, varieties and forms of Robinia: R. viscosa var. hartwegii (Koehne) Ashe; R. neomexicana var. rusbyi; R. neomexicana var. neomexicana; R. neomexicana f. pale pink; R. neomexicana f. pale purple; R. pseudoacacia L .; R. pseudoacacia f. pyramidalis (Pepin) Rehd.; R. pseudoacacia f. umbraculifera (DC) Rehd. and R. pseudoacacia x R. neomexicana.

Meteorological conditions with a general tendency to an increase in temperatures were observed during the research period on the territory of the Volgograd agglomeration. The graph based on the data of average annual temperatures for the entire period of meteorological observations illustrates these processes (Figure 1). The trend line of this chart is calculated using Formula 1.

$$
y=0,0353(x-1943)+6,8778
$$

Calculations show that the average annual temperatures during the study period were close to the trend line and even dropped below the average. 


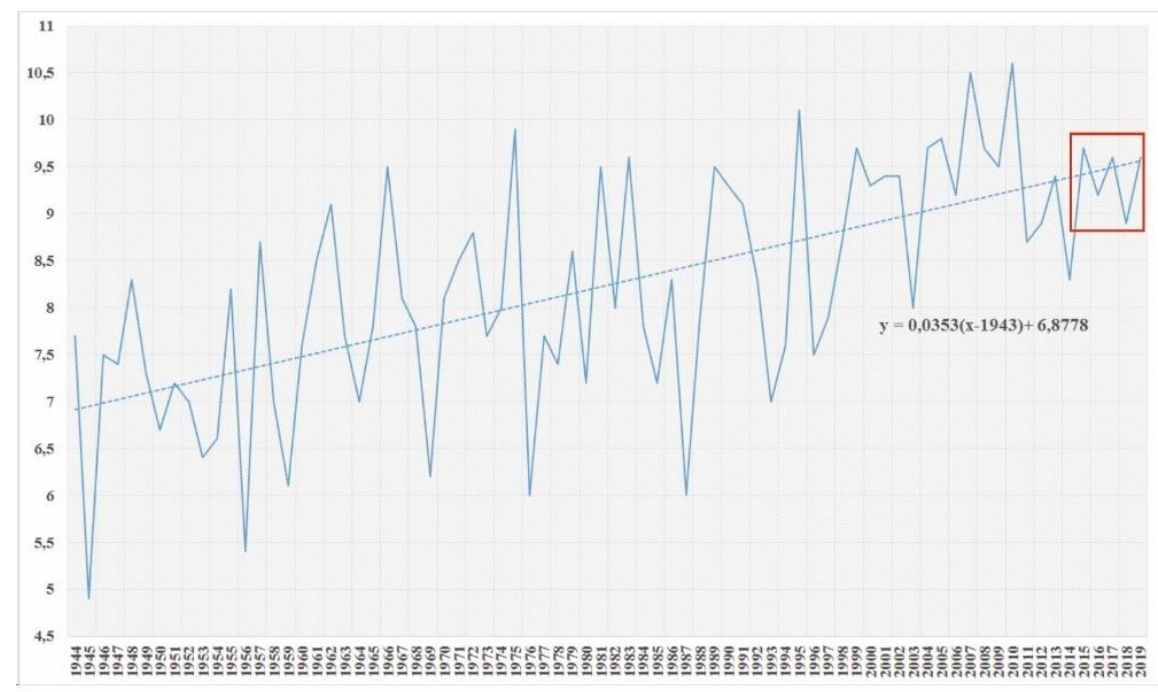

$\square$ Период исследований (2015-2020гг)

Fig. 1. Average annual temperatures according to the data of the meteorological station (Volgograd) for the entire period of meteorological observations 1944-2019 and the period of research in 20152020.

The features of the seasonal rhythms of development were studied according to accepted methods. The characteristic of passaging phenological phases of development of the studied plants was carried out according to the accepted classification: early beginners and early endings, early beginners and late endings, late beginners and early endings, and late beginners and late endings of the growing season. The early or late onset and end of the growing season were determined to the average timing of phenophases typical for flowering woody plants of the Volgograd agglomeration: the beginning of the growing season (bud opening, Pch2) - 17.04 and the end of the growing season (beginning of leaf fall, L3) - 12.10 .

We carried out a comprehensive assessment of correspondence of the seasonal rhythms of development to the climatic characteristics of the introduction point in terms of phenological atypicality. Phenological atypicality is calculated according to advance or lag of the seasonal rhythms of development of representatives of the genus Robinia from the optimal duration of the growing season, calculated from the perennial array of phenodates for 170 species, varieties and forms of flowering woody plants cultivated in the dendrological collections of Volgograd.

For non-flowering forms of $\mathrm{R}$. pseudoacacia $\mathrm{f}$. pyramidalis (Pepin) Rehd, and $\mathrm{R}$. pseudoacacia f. umbraculifera (DC) Rehd. the calculation was carried out according to the phenological phases of vegetative development: Pch1 - bud swelling, Pch2 - bud opening, Pb1 the beginning of linear growth of shoots, $\mathrm{Pb} 2$ - the end of linear growth of shoots, $\mathrm{O} 1$ - the beginning of lignification of shoots, O2 - complete lignification of shoots, L1 - separation of leaves, L2 - the appearance of autumn leaf color, L3 - the beginning of autumn leaf fall L4 - the end of leaf fall. For the rest of the representatives (except for vegetative ones), we used the main generative phases in the calculations: $\mathrm{C} 1$ - budding, $\mathrm{C} 2$ - the beginning of flowering, $\mathrm{C} 3$ - the end of flowering, $\mathrm{Pl}$ - ripening of fruits.

The indicator of phenological atypicality (F1) reflects deviation in the onset of phenological phases of development from the average statistical norm (boundaries from -1 to +1 or from $-\sigma$ to $+\sigma$ ), and is calculated by formula 2 .

$$
F_{1}=\frac{1}{n} \sum \frac{a_{i}-M_{i}}{\delta}
$$


where:

F1 - indicator of atypicality, considering the signs of deviations; a - average dates of the onset of phenological phases of development of the studied plants;

M, $\sigma$ - media and standard deviations (sigma) for each phenophase of the entire phenodate massif (general population) of flowering woody plants cultivated in dendrological collections of the Volgograd agglomeration;

$\mathrm{i}$ - serial number of the phenological phase; $\mathrm{n}$ is the number of studied phenophases.

Plants with a phenological atypicality index from -1 to +1 have the optimal terms of development under this technique. Plants with a lower atypical index are more abundant during the growing season, an indicator above +1 shows an insufficient duration of the growing season for this plant (Table 1).

Table 1. The scale for assessing the inconsistency of the phenology of introduced species with the climate of the secondary area.

\begin{tabular}{|c|c|}
\hline $\begin{array}{c}\text { Indicator of } \\
\text { phenological } \\
\text { atypicality }\end{array}$ & Biological characteristics of plants \\
\hline Less than -3 & $\begin{array}{l}\text { The growing season of the secondary range is not fully occupied, it can } \\
\text { grow in much more harsh conditions }\end{array}$ \\
\hline-2 to -3 & $\begin{array}{l}\text { The growing season of the secondary range is not fully occupied, it can } \\
\text { grow in much more harsh conditions }\end{array}$ \\
\hline-1 to -2 & Fits in the growing season with some excess, can grow in colder climates \\
\hline 0 to -1 & $\begin{array}{l}\text { It is in the upper half of the normal (supernorm) or optimum for the } \\
\text { realization of its phenophases; the development cycle corresponds to the } \\
\text { growing season of the place of introduction }\end{array}$ \\
\hline+1 to 0 & In the lower half of the normal area \\
\hline+2 to +1 & $\begin{array}{l}\text { Does not fit into phenology during the growing season, freezes during } \\
\text { severe winters }\end{array}$ \\
\hline+3 to +2 & $\begin{array}{l}\text { The duration of the growing season, the ecological conditions of the } \\
\text { environment of the place of growth are qualitatively or quantitatively } \\
\text { insufficient for the normal development cycle of an introduced species }\end{array}$ \\
\hline More than +3 & $\begin{array}{l}\text { Environmental conditions significantly do not correspond to the rhythm of } \\
\text { life of the introduced species, which usually freezes out in the first year } \\
\text { after planting. }\end{array}$ \\
\hline
\end{tabular}

We processed data in Excel using standard algorithms: arithmetic means with absolute and relative errors; standard deviations. Basic statistics were calculated using the analysis of variance data.

An indirect comparative characteristic of the potential winter hardiness of species, varieties, and forms of the genus Robinia was assessed by the duration of shoot growth. We determined the end of shoot growth by the phenological phase $(\mathrm{Pb} 2)$ and the phase of complete lignification of the shoots $(\mathrm{O} 2)$. Three phenogroups of all plants according to the duration of shoot growth: with a short, medium and long period of shoot growth.

The decorative properties were assessed in terms of the onset, end and total duration of flowering. Marked the beginning and end of mass flowering, and also repeated flowering throughout the growing season. Observational data are presented as a graphical phenospectrum to visualize the regularities of passaging phenological phases of generative development. 


\section{Results}

The beginning of plant vegetation is one of the key indicators of potential winter hardiness [10]. The average date of the beginning of the growing season (budding phase) for flowering woody plants cultivated in the Volgograd agglomeration falls on April 17, with a standard deviation of 15.58 (table 2). The optimal timing for this phenological phase is between April 1 and May 2. The beginning of the growing season of representatives of the generic complex Robinia falls on April 18 - 27 (table 3). All species, varieties and forms of this genus begin the growing season at the optimal time, but about the average date (April 17), they have a late start of the growing season. This feature is explained by the late onset of the growing season of thermophilic species.

Comparative analysis shows that robinia forms R. pseudoacacia f. pyramidalis and $\mathrm{R}$. pseudoacacia f. umbraculifera grow later than others. Late onset of the growing season is due to internal genetic mechanisms and external damaging environmental factors. These forms have the lowest winter hardiness; negative winter temperatures annually cause damage to the shoots in these plants of varying degrees. Partial freezing of annual and perennial shoots slows down the course of the spring phenological phases of development. Damaged plants need more time to redistribute the preserved nutrients and form the hormonal background necessary for the beginning of the growing season.

Table 2. The timing of the onset of the main phenological phases of the development of flowering woody plants in the greenery plantings of the Volgograd agglomeration.

\begin{tabular}{|l|c|c|c|c|c|c|c|c|c|c|c|c|c|c|}
\hline & Ph1 & Ph2 & Pb1 & Pb2 & O1 & O2 & L1 & L2 & L3 & L4 & C1 & C2 & C3 & P1 \\
\hline $\begin{array}{l}\text { Average dates } \\
\text { general } \\
\text { population), }\end{array}$ & 11.04 & 17.04 & 25.04 & 10.07 & 12.06 & 9.08 & 21.04 & 05.10 & 12.10 & 03.11 & 05.05 & 16.05 & 02.06 & 01.08 \\
\hline $\begin{array}{l}\text { Arithmetic mean } \\
\text { error, } \mathbf{m}\end{array}$ & $\pm 0,49$ & $\pm 0,48$ & $\pm 0,46$ & $\pm 1,16$ & $\pm 0,74$ & $\pm 0,48$ & $\pm 1,08$ & $\pm 0,72$ & $\pm 1,03$ & $\pm 1,30$ & $\pm 0,83$ & $\pm 1,06$ & $\pm 1,73$ & $\pm 1,63$ \\
\hline $\begin{array}{l}\text { Standard } \\
\text { deviation, } \boldsymbol{\sigma}\end{array}$ & 13,71 & 15,58 & 12,78 & 32,33 & 20,76 & 30,17 & 16,02 & 20,06 & 28,91 & 15,39 & 23,12 & 29,59 & 35,15 & 45,84 \\
\hline Optimal $\mathbf{X} \pm \boldsymbol{\sigma}$ & 28.03 & 01.04 & 12.04 & 7.06 & 22.05 & 09.07 & 04.04 & 14.09 & 13.09 & 18.10 & 11.04 & 16.04 & 27.04 & 16.06 \\
02.05 & 07.05 & 11.08 & 02.07 & 08.08 & 07.05 & 25.10 & 09.11 & 18.11 & 28.05 & 14.07 & 07.07 & 15.09 \\
\hline
\end{tabular}

Table 3. The timing of the onset of the main phenological phases of the development of representatives of the genus Robinia in the plantations of the Volgograd agglomeration.

\begin{tabular}{|l|c|c|c|c|c|c|c|c|c|c|c|c|c|c|}
\hline & Ph1 & Ph2 & Pb1 & Pb2 & O1 & O2 & L1 & L2 & L3 & L4 & C1 & C2 & C3 & PI \\
\hline $\begin{array}{l}\text { R. } \\
\text { pseudoacaci } \\
\text { a }\end{array}$ & 14.04 & 21.04 & 28.04 & 02.09 & 20.06 & 17.09 & 25.04 & 15.10 & 24.10 & 14.11 & 06.05 & 17.05 & 28.05 & $\begin{array}{c}21.0 \\
8\end{array}$ \\
\hline $\begin{array}{l}\text { R. } \\
\text { neomexicana } \\
\text { var. rusbyi }\end{array}$ & 12.04 & 18.04 & 26.04 & 07.08 & 18.06 & 22.08 & 22.04 & 16.10 & 26.10 & 08.11 & 11.05 & 22.05 & 01.06 & $\begin{array}{c}28.0 \\
8\end{array}$ \\
\hline $\begin{array}{l}\text { R. viscosa } \\
\text { var. hartweg } \\
\text { ii }\end{array}$ & 16.04 & 23.04 & 29.04 & 15.09 & 21.07 & 30.09 & 27.04 & 17.10 & 27.10 & 17.11 & 03.05 & 14.05 & 16.09 & $\begin{array}{c}14.0 \\
9\end{array}$ \\
\hline $\begin{array}{l}\text { R. } \\
\text { pseudoacaci } \\
\begin{array}{l}\text { a x } \\
\text { R. } \\
\text { neomexicana. }\end{array}\end{array}$ & 13.04 & 21.04 & 28.04 & 12.08 & 20.06 & 27.08 & 25.04 & 10.10 & 18.10 & 08.11 & 11.05 & 22.05 & 01.06 & $\begin{array}{c}21.0 \\
8\end{array}$ \\
\hline $\begin{array}{l}\text { R. } \\
\text { neomexicana } \\
\text { f. pale purple }\end{array}$ & 12.04 & 19.04 & 27.04 & 08.08 & 19.06 & 17.08 & 23.04 & 09.10 & 17.10 & 09.11 & 11.05 & 22.05 & 01.06 & $\begin{array}{c}28.0 \\
8\end{array}$ \\
\hline $\begin{array}{l}\text { R. } \\
\text { neomexicana } \\
\text { f. pale pink }\end{array}$ & 15.04 & 21.04 & 28.04 & 08.08 & 20.06 & 23.08 & 25.04 & 09.10 & 17.10 & 09.11 & 11.05 & 22.05 & 01.06 & $\begin{array}{c}28.0 \\
8\end{array}$ \\
\hline \begin{tabular}{l} 
R. \\
\hline
\end{tabular} & 19.04 & 26.04 & 02.05 & 04.09 & 25.07 & 17.09 & 30.04 & 25.10 & 1.11 & 20.11 & - & - & - & - \\
\hline
\end{tabular}




\begin{tabular}{|l|l|l|l|l|l|l|l|l|l|l|l|l|l|c|}
\hline & Ph1 & Ph2 & Pb1 & Pb2 & O1 & O2 & L1 & L2 & L3 & L4 & C1 & C2 & C3 & P1 \\
\hline $\begin{array}{l}\text { pseudoacaci } \\
\text { a } \\
\text { f. } \\
\text { pyramidalis }\end{array}$ & & & & & & & & & & & & & & \\
\hline $\begin{array}{l}\text { R. } \\
\text { pseudoacaci } \\
\text { a } \\
\text { f. } \\
\text { umbraculifer } \\
\text { a }\end{array}$ & 21.04 & 27.04 & 03.05 & 09.09 & 21.07 & 22.09 & 01.05 & 27.10 & 5.11 & 22.11 & - & - & - & - \\
\hline
\end{tabular}

Phenological phases reflecting the processes of spring development of flowering woody plants in the conditions of the Volgograd agglomeration occur relatively synchronously. The standard deviation $(\sigma)$ of scattering values ranges from 12.78 (phase of the beginning of shoot growth, $\mathrm{Pb} 1$ ) to 16.02 (phase of separation of leaves, L1). All members of the genus Robinia fit within the optimal time frame, despite the small values of the standard deviation. Phases $\mathrm{Pb} 1, \mathrm{Ph} 1$ and $\mathrm{L} 1$ correlate with the beginning of the growing season $(\mathrm{Ph} 2)$, lag in the development of forms R. pseudoacacia and R. viscosa var. hartwegii to other species are slightly reduced by the beginning of shoot growth.

The end of growth and full ripening of shoots are the phenological phases of vegetative development that vary in terms of time. These phases determine the ability of plants to thrive in more severe climates. The potential winter hardiness of plants depends on the timely completion of growth and complete ripening of the shoots. The end of growth and lignification of shoots of typical representatives, forms and hybrids of $\mathrm{R}$. neomexicana occurs at the optimum time, while the corresponding phases of R. pseudoacacia and R. viscosa var. hartwegii (Figure 1). Although the natural distribution areas of all representatives of the genus Robinia are found in more southern latitudes, passaging these phenological phases in the conditions of the Volgograd agglomeration is close to the optimal time. This is because of the formation of several genetic adaptations resulting from the change of several generations of plants under conditions of introduction.

The timeliness of passaging the generative phases of development is an important characteristic of the adaptation of plants to new conditions of existence at the population and species levels $[11,12]$. The beginning and end of flowering and fruit ripening are the most variable phases of seasonal development. Relative to the average date (May 16), most species and varieties of the genus Robinia have a late onset of flowering. The absolute leader in flowering time is R. viscosa var. hartwegii. Robinia sticky is the only species that has a long summer-autumn flowering ending in mid-September. This feature is rarely found among woody plants, therefore, in the $\mathrm{C} 3$ phase, sticky robinia does not fit into the optimal time frame (27.04 - 07.07) (Figure 2). Deviation in phenological flowering rhythms harms generative development. We note this species has the lowest fruit set [13]. Ripening of fruits of R. viscosa var. hartwegii is observed later in other species. This is because fruit setting occurs during spring and partly summer flowering. Flowering in the second half of summer and autumn rarely leads to fruit setting, therefore the phase of the end of flowering in mid-September coincides with the phase of fruit ripening. 


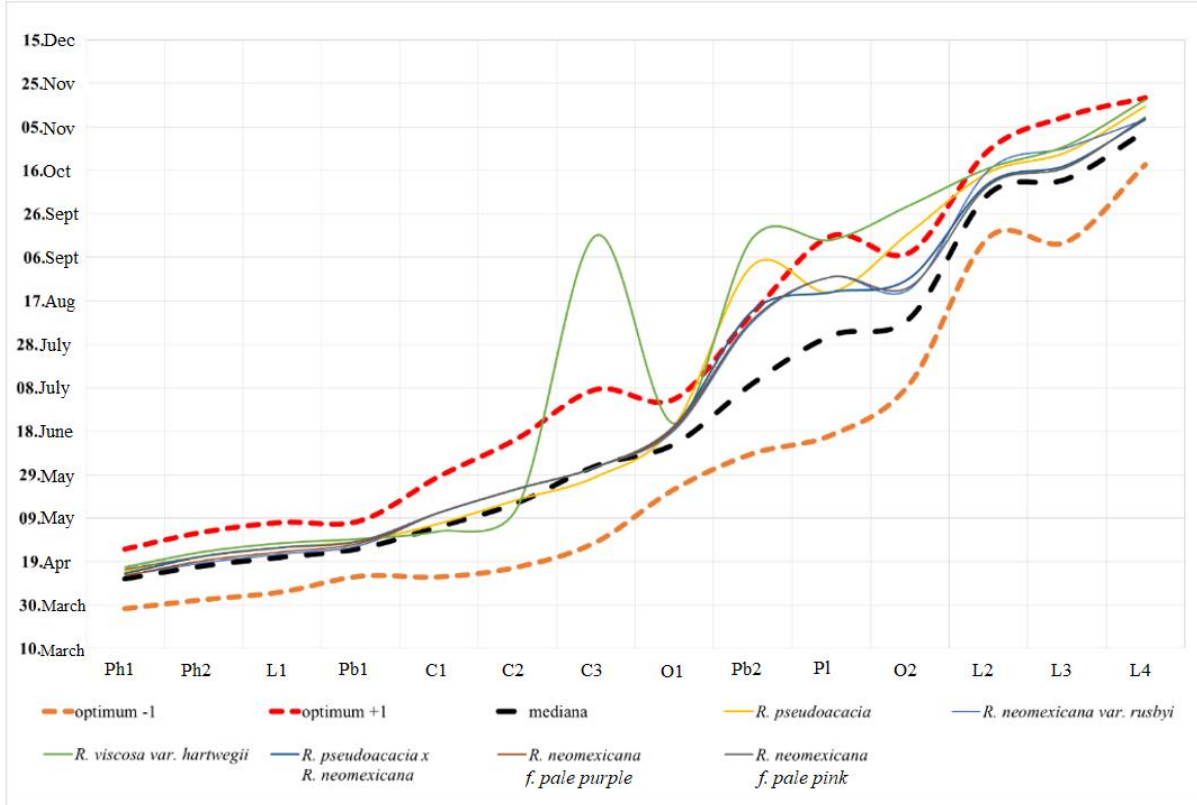

Fig. 2. Correspondence between the average timing of the onset of the phenological phases of development of representatives of the genus Robinia and the optimal timing of the development of flowering woody plants of the Volgograd agglomeration.

Not all members of the genus Robinia are capable of generative development. R. pseudoacacia f. pyramidalis and R. pseudoacacia f. umbraculifera are incapable of flowering and fruiting. These forms reproduce only vegetatively under culture conditions. They are incapable of forming genetic adaptations to new cultivation conditions and are of no interest in the creation of sustainable self-renewing tree plantations. The longevity of their existence depends on the correspondence of the seasonal rhythms of vegetative development to the climatic characteristics of the introduction. Phenological atypicality for R. pseudoacacia f. pyramidalis and R. pseudoacacia f. umbraculifera, we calculated only by phenological phases characterizing the features of vegetative development.

The phases of the appearance of autumn leaf color [14], the beginning and end of leaf fall [15] are of great importance for assessing adaptation of plants to new climatic conditions. The beginning of autumn leaf fall (L3) is the end of the growing season of flowering woody plants. The average date of the end of the growing season in the Volgograd urban agglomeration falls on October 12. The onset of leaf fall for all members of the genus Robinia is between 17 October and 5 November.

Although the studied species fit into the optimal developmental periods, they are classified as late beginners and late terminators of the growing season compared to the average period. This feature is typical for many plants of southern origin. Despite the different dates of the beginning and end of the growing season, the total duration of the growing season differs slightly and for different representatives ranges from 179 (R. neomexicana f. pale pink) to 192 days (R. pseudoacacia f. umbraculifera).

An important indicator of potential winter hardiness is the duration of shoot growth $(\mathrm{Pb} 2-\mathrm{Pb} 1)$. Plants with a short growing period are usually more winter-hardy [16]. The rapid end of shoot growth contributes to their timely ripening. Species, varieties and forms can be divided into three groups according to the duration of growth. Representatives, forms, varieties, and also hybrids of R. neomexicana (102-106 days) are distinguished by a short growth period. The average duration of shoot growth is observed in R. pseudoacacia 
and its forms (125-129 days). The longest duration was observed in representatives of R. viscosa var. hartwegii (138 days) (Figure 3).

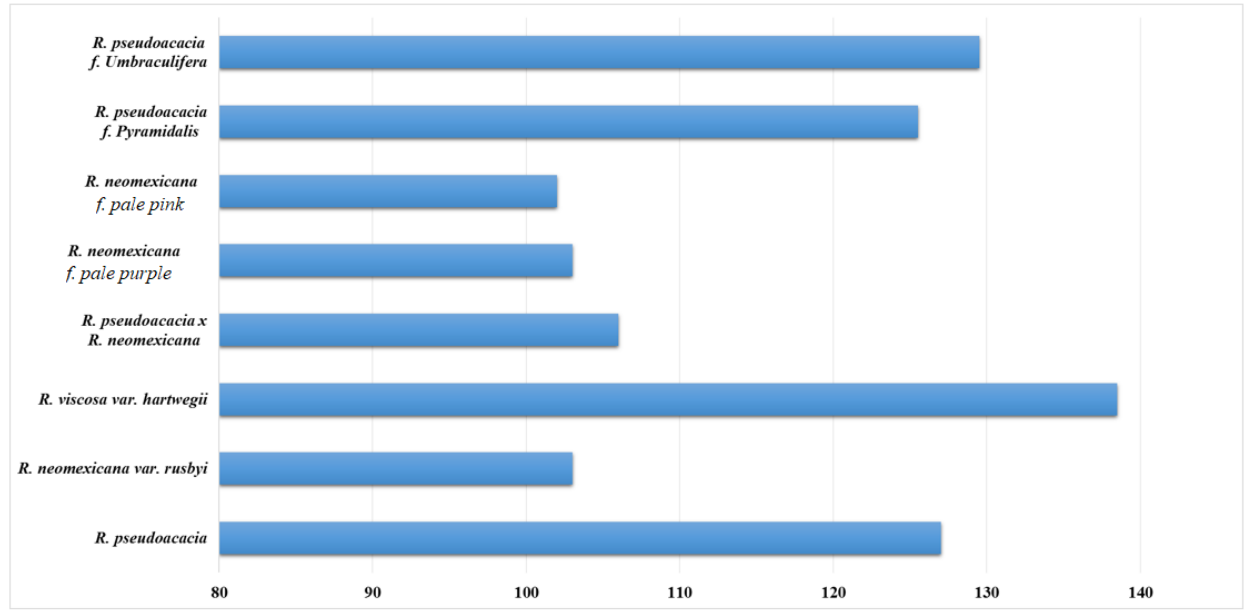

Fig. 3. Duration of growth of shoots of species, varieties and forms of the genus Robinia in days.

Calculations of the phenological atypicality index for R. pseudoacacia f. umbraculifera and R. pseudoacacia f. pyramidalis were carried out in ten phenological phases of development according to the following formulas: 3,4 .

Phenological atypicality R. pseudoacacia f. umbraculifera (formula 3 ).

$$
\begin{aligned}
& \frac{1}{10} \sum_{\frac{21.04-11.04}{13,71}}+\frac{27.04-17.04}{15,58}+\frac{03.05-25.04}{12,78}+\frac{09.09-10.07}{32,33}+\frac{21.07-12.07}{20,76}+\frac{22.09-9.08}{30,17}+ \\
& \frac{1.05-21.04}{16,02}+\frac{27.10-5.10}{20,06}+\frac{5.11-12.10}{28,91}+\frac{22.11-3.11}{15,39}=+0,96
\end{aligned}
$$

Phenological atypicality R. pseudoacacia f. pyramidalis (formula 4).

$$
\begin{aligned}
& \frac{1}{10} \sum_{\frac{19.04-11.04}{13,71}}+\frac{26.04-17.04}{15,58}+\frac{02.05-25.04}{12,78}+\frac{04.09-10.07}{32,33}+\frac{25.07-12.07}{20,76}+\frac{17.09-9.08}{30,17}+ \\
& \frac{30.04-21.04}{16,02}+\frac{25.10-5.10}{20,06}+\frac{1.11-12.10}{28,91}+\frac{20.11-3.11}{15,39}=+0,87
\end{aligned}
$$

The calculation for the rest of the representatives was carried out according to 14 indicators according to formulas 5, 6, 7, 8, 9, 10 .

Phenological atypicality R. neomexicana f. pale pink (formula 5).

$$
\begin{aligned}
& \frac{1}{14} \sum_{\frac{15.04-11.04}{13,71}}+\frac{21.04-17.04}{15,58}+\frac{28.04-25.04}{12,78}+\frac{08.08-10.07}{32,33}+\frac{20.06-12.07}{20,76}+\frac{23.08-9.08}{30,17}+ \\
& \frac{25.04-21.04}{16,02}+\frac{09.10-5.10}{20,06}+\frac{17.10-12.10}{28,91}+\frac{09.11-3.11}{15,39}+\frac{11.05-5.05}{23,12}+\frac{22,05-16,05}{29,59}+\frac{01.06-2.06}{35,15}+ \\
& \frac{28.08-01.08}{45,84}=+0,35
\end{aligned}
$$


Phenological atypicality R. neomexicana f. pale purple (formula 6).

$$
\begin{aligned}
& \frac{1}{14} \sum_{\frac{12.04-11.04}{13,71}}+\frac{19.04-17.04}{15,58}+\frac{27.04-25.04}{12,78}+\frac{08.08-10.07}{32,33}+\frac{19.06-12.07}{20,76}+\frac{17.08-9.08}{30,17}+ \\
& \frac{23.04-21.04}{16,02}+\frac{09.10-5.10}{20,06}+\frac{17.10-12.10}{28,91}+\frac{09.11-3.11}{15,39}+\frac{11.05-5.05}{23,12}+\frac{22,05-16,05}{29,59}+\frac{01.06-2.06}{35,15}+ \\
& \frac{28.08-01.08}{45,84}=+0,30
\end{aligned}
$$

Phenological atypicality R. pseudoacacia x R. neomexicana (formula 7).

$$
\begin{aligned}
& \frac{1}{14} \sum_{1} \frac{13.04-11.04}{13,71}+\frac{21.04-17.04}{15,58}+\frac{28.04-25.04}{12,78}+\frac{12.08-10.07}{32,33}+\frac{20.06-12.07}{20,76}+\frac{27.08-9.08}{30,17}+ \\
& \frac{25.04-21.04}{16,02}+\frac{10.10-5.10}{20,06}+\frac{28.10-12.10}{28,91}+\frac{08.11-3.11}{15,39}+\frac{11.05-5.05}{23,12}+\frac{22,05-16,05}{29,59}+\frac{01.06-2.06}{35,15}+ \\
& \frac{21.08-01.08}{45,84}=+0,35
\end{aligned}
$$

Phenological atypicality R. viscosa var. hartwegii (formula 8).

$$
\begin{aligned}
& \frac{1}{14} \sum_{\frac{16.04-11.04}{13,71}}+\frac{23.04-17.04}{15,58}+\frac{29.04-25.04}{12,78}+\frac{15.09-10.07}{32,33}+\frac{21.07-12.07}{20,76}+\frac{30.09-9.08}{30,17}+ \\
& \frac{27.04-21.04}{16,02}+\frac{17.10-5.10}{20,06}+\frac{27.10-12.10}{28,91}+\frac{17.11-3.11}{15,39}+\frac{3.05-5.05}{23,12}+\frac{14,05-16,05}{29,59}+\frac{16.09-2.06}{35,15}+ \\
& \frac{14.09-01.08}{45,84}=+0,84
\end{aligned}
$$

Phenological atypicality R. neomexicana var. rusbyi (formula 9).

$$
\begin{aligned}
& \frac{1}{14} \sum_{\frac{12.04-11.04}{13,71}}+\frac{18.04-17.04}{15,58}+\frac{26.04-25.04}{12,78}+\frac{07.08-10.07}{32,33}+\frac{18.06-12.07}{20,76}+\frac{22.08-9.08}{30,17}+ \\
& \frac{22.04-21.04}{16,02}+\frac{16.10-5.10}{20,06}+\frac{26.10-12.10}{28,91}+\frac{08.11-3.11}{15,39}+\frac{11.05-5.05}{23,12}+\frac{22,05-16,05}{29,59}+\frac{01.06-2.06}{35,15}+ \\
& \frac{28.08-01.08}{45,84}=+0,32
\end{aligned}
$$

Phenological atypicality $R$. pseudoacacia L. (formula 10).

$$
\begin{aligned}
& \frac{1}{14} \sum_{\frac{14.04-11.04}{13,71}}+\frac{21.04-17.04}{15,58}+\frac{28.04-25.04}{12,78}+\frac{2.09-10.07}{32,33}+\frac{20.06-12.07}{20,76}+\frac{17.09-9.08}{30,17}+ \\
& \frac{25.04-21.04}{16,02}+\frac{15.10-5.10}{20,06}+\frac{24.10-12.10}{28,91}+\frac{14.11-3.11}{15,39}+\frac{6.05-5.05}{23,12}+\frac{17,05-16,05}{29,59}+\frac{28.05-2.06}{35,15}+ \\
& \frac{21.08-01.08}{45,84}=+0,47
\end{aligned}
$$

As a result of the calculations, we found that the phenological atypicality indicator for all studied species, varieties and forms in the conditions of the Volgograd urban agglomeration is in the range from 0 to +1 . The cycle of their development corresponds to the growing season of the place of introduction and is in the lower half of the normal range (Figure 4).

All representatives of the genus Robinia (except for R. pseudoacacia f. Pyramidalis and R. pseudoacacia $\mathrm{f}$. umbraculifera) are decorative flowering plants [13]. The study of the seasonal rhythms of generative development determined the periods of their maximum decorativeness and gave a comparative description of the timing of the beginning and end of flowering. R. viscosa var. hartwegii. Typical representatives and forms of $\mathrm{R}$. neomexicana are distinguished by the late onset of flowering (May 22). Robinia pseudoacacia blooms a little earlier than R. neomexicana (May 17). Seasonal rhythms of development of hybrid forms of R. pseudoacacia x R. neomexicana inherit the phenological 
features of R. neomexicana. The average date for the beginning of flowering of hybrid forms also falls on May 22. Table 4 shows that R. viscosa var. hartwegii has the longest flowering. After the first spring-summer, there is usually a break of 2-3 weeks, after which the repeated summer-autumn flowering begins.

Table 4. Phenological spectra of seasonal developmental rhythms of representatives of the genus Robinia.

\begin{tabular}{|c|c|c|c|c|c|c|c|c|}
\hline & April & May & June & July & August & $\begin{array}{c}\text { Septembe } \\
\mathbf{r}\end{array}$ & October & November \\
\hline $\begin{array}{l}R . \\
\text { pseudoacacia }\end{array}$ & & & & & & & & \\
\hline $\begin{array}{l}R . \\
\text { neomexicana } \\
\text { var. rusbyi }\end{array}$ & & & & & & & & \\
\hline $\begin{array}{l}\text { R. viscosa } \\
\text { var. hartwegii }\end{array}$ & & & & & & & & \\
\hline $\begin{array}{l}R . \\
\text { pseudoacacia } \\
x \\
R . \\
\text { neomexicana }\end{array}$ & & & & & & & & \\
\hline $\begin{array}{l}R . \\
\text { neomexicana } \\
\text { f. pale purple }\end{array}$ & & & & & & & & \\
\hline $\begin{array}{l}R . \\
\text { neomexicana } \\
\text { f. pale pink }\end{array}$ & & & & & & & & \\
\hline $\begin{array}{l}R . \\
\text { pseudoacacia } \\
\text { f. pyramidalis }\end{array}$ & & & & & & & & \\
\hline $\begin{array}{l}R . \\
\text { pseudoacacia } \\
\text { f. } \\
\text { umbraculifera }\end{array}$ & & & & & & & & \\
\hline
\end{tabular}

\begin{tabular}{|l|l|l|l|l|l|l|}
\hline Winter rest & $\begin{array}{l}\text { Swelling of the } \\
\text { buds }\end{array}$ & Vegetation & Bloom & $\begin{array}{l}\text { Autumn leaf } \\
\text { color }\end{array}$ & Falling leaves \\
\hline
\end{tabular}

\section{Discussion}

Bioecological characteristics for phenological phases (beginning and end of the growing season) and the calculation of the duration of shoot growth and the growing season sometimes is contradictory. According to the longest duration of shoot growth, R. viscosa var. hartwegii should have the lowest winter hardiness. However, in terms of the duration of the growing season and the timing of the beginning of the growing season, the forms of R. pseudoacacia are less winter-hardy. An aim assessment of the correspondence of the seasonal rhythms of development to the climatic conditions of the region can be carried out only by the atypicality indicator, which assesses the features of passaging the entire complex of phenological phases of development.

Because of a comparative analysis of absolute values, we found that the forms, varieties, and hybrids of R. neomexicana have the lowest atypicality. The low atypicality index shows high correspondence between the seasonal rhythms of the development of these plants to the climatic conditions of the region. Representatives of R. pseudoacacia $f$. 
Umbraculifera (+0.96), R. pseudoacacia f. Pyramidalis (+0.87), R. viscosa var. hartwegii $(+0.84)$ have the highest atypicality index. A high value of atypicality shows that the rhythms of their seasonal development are at the border of the normal range and approach the values of $+1-+2$, characteristic of non-frost-resistant plants (Fig. 4).

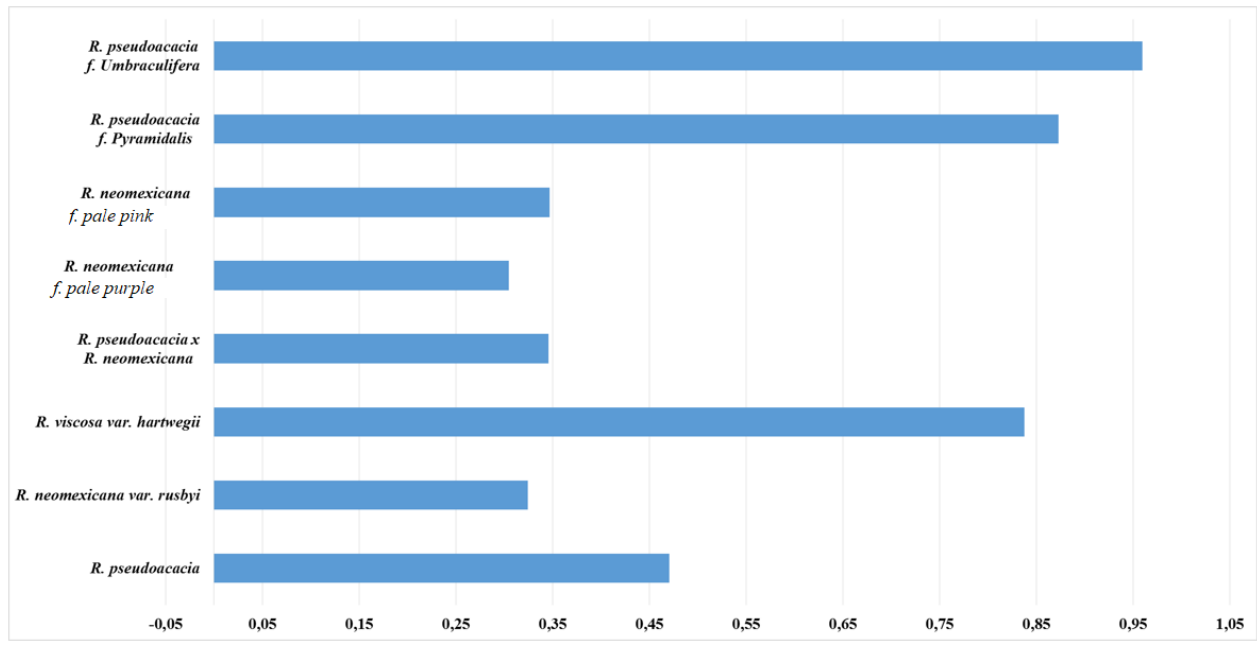

Fig. 4. Indicator of phenological atypicality of species, varieties and forms of the genus Robinia.

The bioecological characteristics of plants in terms of phenological parameters are confirmed by the data of visual observations [17]. The most thermophilic forms are R. pseudoacacia. R. viscosa var. hartwegii has a relatively low winter hardiness. Despite similar indicators of phenological atypicality, winter damaging factors affect the growth of these plants in different ways. Periodic freezing of the branches of R. pseudoacacia $f$. pyramidalis and R. pseudoacacia f. umbraculifera lead to a loss of crown geometry and, as a result, a complete loss of decorative properties. Winter injuries R. viscosa var. hartwegii gradually removes the apical dominance of the shoots, which is why an umbrella or wide domed crown forms. This feature does not reduce the ornamental properties of plants and leads to the appearance of a very promising crown shape that is qualitatively new for this generic complex.

\section{Conclusion}

The study found that most of the phenological phases of representatives of the genus Robinia occur at the optimal time for the seasonal development of flowering woody plants in the urban landscaping of the Volgograd agglomeration. The indicator of phenological atypicality of these representatives $(+1-0)$ shows that the cycles of seasonal development correspond to the growing season of the place of introduction and are in the lower half of the normal range. R. viscosa var. hartwegii, R. pseudoacacia f. pyramidalis and $R$. pseudoacacia $\mathrm{f}$. umbraculifera have an atypical score ranging from +0.8 to +1 . Seasonal developmental rhythms are at the edge of the normal range and approach the values of +1 +2 , which is typical for non-frost-resistant plants. The northern border of the range of a wide culture of these species is at the latitude of the Volgograd agglomeration, and further advancement to regions with a more severe climate is possible only in experimental plantations or as an additional assortment. 
Regarding the average statistical timing of seasonal development, all representatives of the genus Robinia belong to the group of late beginners and late terminators of the growing season. This feature is typical for many plants of southern origin.

According to the duration of shoot growth, the studied species, varieties and forms were divided into three groups. Typical representatives, forms and varieties of R. neomexicana, hybrid forms of $\mathrm{R}$. pseudoacacia $\mathrm{x}$ R. neomexicana have a short growth period. R. pseudoacacia and its forms have an average period of shoot growth. R. viscosa var. hartwegii have the longest duration of shoot growth.

The revealed patterns of seasonal developmental rhythms determine the potential winter hardiness of the studied plants. All forms, varieties and hybrids of R. neomexicana, and typical representatives of $R$. pseudoacacia have a phenological atypicality index from +0.3 to +0.47 . This indicator shows the potential winter hardiness, the border of the area of their wide culture can pass north of the latitude of the Volgograd agglomeration. The most winter-hardy are all representatives of R. neomexicana, hybrid forms of R. pseudoacacia $x$ R. neomexicana. The phenological atypicality index of these plants ranges from +0.3 to +0.35 . These species and forms can be successfully grown in the north of the Volgograd region.

The study of the seasonal rhythms of generative development determined the periods of maximum decorativeness of the representatives of the generic complex Robinia, and to carry out a comparative characteristic in terms of the beginning and end of the flowering period. Research has shown that R. viscosa var. hartwegii has the longest flowering period.

We have researched on the State Assignment "Scientific bases and technologies of enrichment of dendroflora of forest reclamation complexes with ecologically valuable trees and shrubs to prevent degradation and desertification of territories" (Reg. No. 121041200197-8).

\section{References}

1. M. Merlin, A. Duputié, I. Chuine, Forest Ecology and Management, 410 (2018)

2. L.R. Iverson, M.W. Schwartz, A.M. Prasad, Global Ecology and Biogeography, 13 (2014)

3. C.M. Zohner, S.S. Renner, Ecology Letters, 17, 8 (2014)

4. A.L. Lv, Z.G. Huo, J.Y. Yang, Journal of Agrometeorology, 41 (2020)

5. H. Wang, C. Wu, P. Ciais, J. Peñuelas, J. Dai, Y. Fu, Q. Ge, Nature Communications, 11, 1 (2020)

6. B.-B. Chen, Y.-F. Zheng, G.-Q. Zhao, H.-L. Chen, Journal of Plant Resources and Environment, 16, 1 (2007)

7. J. Dai, H Wang, Q. Ge, Journal of Biometeorology, 58, 4 (2014)

8. R.C. Sundrigal, Int. J. Ecol. and Environ, 2 (1990)

9. K. Jabłońska, A. Kwiatkowska-Falińska, B. Czernecki, Journal of Ecology, 63, 3 (2015)

10. S. Xu, W. Xu, W. Chen, X. He, Y. Huang, H. Wen, PLoS ONE, 9, 6 (2014)

11. G.Walkovszky, Journal of Biometeorology, 41, 4 (1998)

12. Y. Du, L. Mao, Journal of Biogeography, 47, 11 (2020)

13. S.E. Lazarev, A.V. Semenyutina, A.I. Belyaev, International Journal of Advanced Trends in Computer Science and Engineering, 9, 4 (2020)

14. G. Liu, X. Chen, Q. Zhang, W. Lang, N. Delpierre, Biology of global change, 24, 8 (2018) 
15. G. Charrier, T. Ameglio, Environmental and Experimental Botany, 72, 3 (2011)

16. E. Prada, J. Climent, R. Alí, R. Díaz, Journal of Botany, 103, 12 (2016)

17. V. D. Mazurenko, Scientific Bulletin of NLTU of Ukraine, 23, 5 (2013) 